\title{
REDD Policy in Indonesia Reality in Grey Area
}

\author{
Submitted: 10 March 2014 \\ Accepted: 30 June 2014
}

\section{Deni Bram}

Faculty of Law Tarumanagara University, Jakarta, Indonesia Deni_up@yahoo.co.id

\begin{abstract}
This note focuses on Reducing Emissions from Deforestation and Forest Degradation (REDD), an international framework that aims to curb carbon emissions by reducing deforestation. Meanwhile international negotiators discuss the environmental benefits of REDD, which will likely be implemented in the Kyoto Protocol's post-2012 commitment period. Indonesia as one of countries with a high rate of deforestation and has large number of tropical forests of course become the main actor in REDD regime. Indonesia policy regarding REDD+ is the first come to response it in the regulation scope. Nowadays Indonesia has a lot of REDD+ project that based on voluntary approach and some of them are already finished. This condition makes the legitimacy of REDD+ regime in Indonesia to be questioned and seemed play in grey area because there is no legally binding formulation about REDD+ in international area but already exist in Ministry of Forestry level. This paper will emphasize some of the main issues related to REDD+ in international and Indonesia context. Firstly, the background on the adoption concept of REDD+ in international discourse and the debate from developed and developing countries perspective about it. Secondly, trace the basic legitimacy of REDD+ implementation in Indonesia based on regulations and stakeholder was involved in REDD+ project. Lastly, the response that should be done from the clearly position of REDD+ in Indonesia. This response was in order to encourage the legitimation of legal instrument and legal institution that can accommodate the implementation of REDD+ projects in Indonesia. This paper will also to conducting REDD+ national concept by doing the lessons learnt on other forest state national policy. The conclusion of this paper can provide a clear position on the implementation of REDD+ in Indonesia starting from the validity of the existing legal policies until give optional model for others countries.
\end{abstract}

Keywords: climate change, legal response, mitigation

\section{Introduction}

According to the United Nations Framework Convention on Climate Change (UNFCCC), climate change occurs when the composition of the global atmosphere is altered, either directly or indirectly, by human activity. Power generation, deforestation, transportation, and agriculture all produce greenhouse gases--such as carbon dioxide--that cause temperatures to rise across the globe. Because climate change is "intricately intertwined with population growth, desertification and land degradation, air and water pollution [and] loss of biodiversity," it has been identified as an international crisis.

The consequences of climate change are especially severe for indigenous peoples, who are among the poorest and most marginalized in the world, and often also live in areas most affected by rising temperature. Because their livelihoods frequently depend upon land use and natural resources, indigenous groups are at great risk as climate change depletes resources and pushes them from their traditional homes.

To combat climate change, the international community has principally focused on reducing the amount of carbon dioxide that is released into the atmosphere by industrial and energy sectors. The focus is now shifting to the reduction of forest carbon emissions, however, as it is recognized that deforestation is a major contributor to climate change. The Intergovernmental Panel on Climate Change (IPCC), a United Nations body containing over 2,000 scientists who analyze evidence on climate change, estimates that the forestry sector is responsible for 17.4 per cent of global GHG emissions, placing it above the transportation and industry sectors, which account for 14 per cent of global emissions each.

Forests are the world's most important terrestrial carbon "sink," or storehouse of carbon. The Earth's carbon naturally cycles through four main sinks: geological, oceanic, terrestrial, and atmospheric. One "goal of climate change initiatives" is to "reduce the amount of carbon in the atmospheric store and increase the amount that is sequestered in one of the other three reservoirs." Forests remove carbon from the atmosphere and sequester it in their biomass and soils, which contain approximately 60 per cent of the carbon that is stored in terrestrial sinks. 
When a forest is destroyed (for example, cut down for timber or burned), the harmful effects are twofold: not only is the carbon sequestered in each tree released into the atmosphere, but also the remaining forest's capacity to absorb carbon from the atmosphere is diminished. As a result, deforestation, which is the "permanent removal of forest cover," contributes significantly to global carbon dioxide emissions. In fact, in "2002 the rate of forest loss in Brazil and Indonesia alone produced four-fifths as many greenhouse gases as the Annex I [developed] countries committed to reduce that year under the Kyoto Protocol."

Because forests are immense carbon sinks, many scientists and policymakers alike agree that they should play an important role in curbing climate change. REDD is the best-developed international proposal for forest conservation. Part I.B. traces the history of REDD, which is expected to be a legally binding part of the post-2012 successor to the Kyoto Protocol. Currently, REDD exists solely as a series of pilot projects that are guided by non-binding international agreements.

\section{REDD Response in Indonesia Law}

\subsection{The Important of REDD}

The United Nations Framework Convention on Climate Change (UNFCCC) climate regime represents perhaps the most highly developed set of agreements and institutions in all of international environmental law. [FN120] Participation in the regime is broad--with nearly all recognized nations actively participating in the UNFCCC and potentially very deep. To achieve the UNFCCC's objective of "stabiliz[ing]

greenhouse gas concentrations in the atmosphere at a level that would prevent dangerous anthropogenic interference with the climate system" will require significant changes in virtually all sectors of economic activity. To achieve this goal equitably, which is often understood to require facilitating economic growth in developing countries to improve the well-being of the world's poor, represents a challenge that is likely to define more than a generation of environmental law.

It is perhaps not surprising, then, that tropical forests have come to be viewed as an appropriate subject of climate regime regulation, and that the emerging REDD program is now seen by many as the best vehicle for effecting change in tropical forests. To succeed, however, this program must be equipped with features that will directly address the underlying drivers of tropical deforestation and the stumbling blocks of prior efforts to address them.

The potential to impact forestry through climate regime mechanisms has been recognized since nearly the inception of the regime, but a potentially effective program to combat deforestation has only recently begun to emerge. Significant diplomatic attention to regulating the forest sector under the UNFCCC first surfaced late in the negotiations leading to *117 the 1997 Kyoto Protocol. During these negotiations, the potential to reduce forest emissions was tabled in favor of an approach concentrating on forests as potential carbon sinks, ultimately defined through complex Clean Development Mechanism (CDM) rules established in the Marrakesh Accords adopted during the first meeting of Kyoto Protocol parties. Essentially, developed countries are permitted to invest in afforestation and reforestation activities (but not anti-deforestation measures) in developing countries as a means of generating CDM credits to offset up to one per cent of their 1990 emissions for compliance with the Kyoto Protocol. The parties excluded reduced deforestation projects from the CDM because of technical uncertainties, difficulty of monitoring, and sovereignty concerns of developing nations. Because of these limitations, the climate regime impact on forestry has been minimal. Further, the Marrakesh Accords adopted an expansive definition of "forest" that easily includes plantation forestry without regard to environmental impacts, which may permit carbon credits to be issued for forestry projects with environmentally deleterious net effects.

Through the work of the Intergovernmental Panel on Climate Change (IPCC) and others, recognition of deforestation as a major source of GHG emissions--roughly equivalent to transportation sector emissions--continued to grow after the adoption of the Marrakesh Accords. The first formal proposal for a mechanism to reward avoided deforestation on the basis of reduced emissions was introduced by the Coalition of Rainforest Nations in 2005 at COP-11. Elements of this proposal, which spawned the now widely used term "REDD," provided the basic building blocks for negotiations toward creating an antideforestation program within the climate regime.

The core idea of REDD is to enable developing countries to receive financial support for reducing GHG emissions from deforestation. Reductions would most likely be measured as the difference between a pre-defined baseline rate of deforestation emissions and a verified reduction in deforestation emissions achieved through measures or projects that comply with REDD requirements. Major mitigation-related issues in the negotiations toward REDD include rules for setting baseline rates of deforestation and ensuring additionally of emissions reductions, preventing leakage of avoided deforestation to other areas, and securing the permanence of emissions reductions.

The REDD concept gained momentum in 2007 at the COP-13 meeting in Bali, Indonesia where the Subsidiary Body for Scientific and Technological Advice (SBSTA) issued a report that encouraged development of a REDD program. The COP formally endorsed the development of reduced emissions from deforestation program in the "Bali roadmap," which established the framework for negotiations toward a post-Kyoto agreement.

After Bali, REDD became the subject of intense negotiations, billions of dollars of investment by governments and non-state organizations, formal proposals by nearly every country that could be affected by the mechanism, and extensive literature. At COP-15 in Copenhagen, the REDD negotiations within the 
Ad-hoc Working Group on Long-Term Cooperative Action (AWG-LCA) were arguably the most successful negotiations of the entire conference. An AWG-LCA draft decision on REDD policy, crafted during COP15 , demonstrates near-agreement on many of the key aspects of REDD. The COP agreed to move forward on REDD at COP-16 in Cancun and the decision that emerged from the AWG-LCA's work in Cancun, a part of the Cancun Agreements, represents the COP's first formal recognition of REDD. To some extent, the decision also reflects consensus on the broad outline of REDD. Nonetheless, major issues remain unresolved, including the role of markets in financing avoided deforestation and the extent of social and ecological safeguards in the program.

An important component of REDD's high profile is its characterization as a low-cost mitigation opportunity. The influential Stern Review helped to develop this characterization by relying on the potential for low-cost near-term emissions reductions to support its economic case for international action to address climate change. In many models of REDD, its cost-effectiveness is enhanced by a market-based system in which REDD activities generate tradable carbon offset credits. However, some countries and commentators have consistently opposed using carbon offset credits to finance REDD, instead pushing for a fund-based approach in which donor nations would provide financing through an international fund.

Notably, developed countries have demonstrated a far greater willingness to fund REDD-related forest improvements than has been evident in any prior forest-related negotiations. For example, the Copenhagen Accord contains explicit agreement on "the need to provide positive incentives to [reduce emissions from deforestation] through the immediate establishment of a mechanism including REDD-plus, to enable the mobilization of financial resources from developed countries."

Increasingly, REDD is viewed as a major opportunity to enable developing countries to make a meaningful contribution to mitigation, which is probably integral to any significant global action on climate change. Recognition of REDD in the Cancun Agreements supports the widespread perception that some form of REDD is virtually certain to play a role in the post-Kyoto approach to climate change, even if the parties do not reach agreement on a comprehensive Kyoto-style agreement.

The emergence of REDD over the next few years will create opportunities to simultaneously address other major environmental and development priorities. REDD could potentially lead to improvements in forest management that promote biodiversity preservation and socioeconomic development. However, this potential may be limited by a view of the forest sector as "low hanging fruit" for cheap near-term emissions reductions.

\subsection{Climate Change Mitigation Issues in Indonesia Legal System}

Indonesia as one of the countries participating in the climate change negotiations would not want to be involved in the dynamics of international environmental law related to climate change. Gait Indonesia in the climate change cannot be observed from the participation in the United Nations Framework Convention On Climate Change in 1992 in Kyoto Protocol forwarded To The United Nations Framework Convention On Climate Change in 1997 up to the discussion - both in the annual discussion forum Conference of the Parties and other related meetings in order to prepare a climate change policy a second commitment period after the Kyoto Protocol.

Regulatory issues related to climate change as a continuation of the approval process of the Government of Indonesia in the International level, Indonesia has ratified the international regulations that followed. The ratification has done well against United Nations Framework Convention on Climate Change through Law No. 6 of 1994 on the Ratification of the United Nations Framework Convention On Climate Change (United Nations Framework Convention on Climate Change Nations) and the Kyoto Protocol to the Constitution of the Republic of Indonesia number 17 Year 2004 on Ratification of the Kyoto Protocol To The United Nations Framework Convention on Climate Change ( Kyoto Protocol Upper Nations Framework Convention - Nations on Climate Change ) .

But a mere step towards ratification of a treaty is not enough. There must bring the importance of assessing the process of transformation that the presence of Law and Decree of the President as the instrument of ratification of the treaty ratification only load and enforceability of the treaty, but did not touch a thing substantial. In the perspective of international law, the law of transformation comes as a form of enforcement of international law into national law to interpret an international treaty as a whole in the national legislation which not only ratification. Even more explicitly stated by William Boyd that the issue of climate change has its own characteristics in the international community is an essential activity in order to bring the transformation of the world order. Boyd said that the context of the issue of climate change is not needed at this time can only be resolved by downloading from the international level to the national level or just do the transplant from one legal system to another legal system alone, although both are important. Boyd metaphorically proposed approach to assemblage of different forms of regulations and institutions at the international level to be implemented at national and sub- national levels. At least there are at least 3 (three) main reasons of the importance of the transformation action.

First, the limitations of international law in the regulation of the legal subject that is limited to the state. This implies that international treaties do not have a holding capacity is strong enough to have a relationship with the subject of national law which consists of a system of national criminal law , national civil law, constitutional law and administrative law. The existence of climate change as a global issue with local originators absolute certainly provides justification for this. 
Second, international law also has limitations when used in a national level if not transformation. The existence of the judiciary at the national level is as a state institution that became the catalyst for the fulfillment of the rights of citizens relying solely on the source of national law.

Third, in several international agreements mandate, either directly or indirectly, to make adjustments to the legislation - national legislation. Even more explicitly determined that the adjustment measures into legislation - national legislation of a country as a form of implementation of the obligations of a country. Whereas in the context of International Environmental Law in general and in particular the Law of Climate Change , a similar view is also presented by William Boyd stated that the transformation in the context of climate change law is absolutely necessary in order to limit the number of greenhouse gas substances at several levels ranging from international, national to local.

One of the interesting things in the dynamics of Indonesian action on climate change is the movement of Indonesia's commitment to climate change mitigation measures. The existence of Indonesia as a country belonging to the Group of Non- Annex countries essentially did not cost Indonesia to conduct a mandatory step in mitigating climate change. However, beginning with the official speeches by President Susilo Bambang Yudhoyono in a meeting of G - 20 in Pittsburgh United States in 2009, Indonesia made a breakthrough to reduce emissions at the global level. On that occasion, President Yudhoyono said Indonesia's commitment to voluntarily reduce emissions by $26 \%$ by 2020 with the condition without foreign aid, and by $41 \%$ with foreign aid is based on the calculation of emissions in 2005. Indonesian Government's commitment to reducing emissions originated from Indonesia acceptance of the outcome of the Copenhagen Accord. This then becomes the basis for the delegation of the Republic of Indonesia (delegation) while attending the annual meeting to discuss measures - measures of climate change. Even through the Unilateral Approach Indonesia -based instruments also delivered information about the Nationally Appropriate Mitigation Actions (NAMAs) from Indonesia to the UNFCCC Secretariat by Chief Executive of the National Council on Climate Change (NCCC) on January 30, 2010 regarding the voluntary emission reduction.

The debate also appears in the declaration of commitment of the Indonesian government regarding mitigation of greenhouse gas. One of the issues debated in the crowded this commitment statement is preliminary data that the source of the ability of the Indonesian government to achieve this commitment. On the one hand the Government of Indonesia said that the commitment to reduce emissions by $26 \%$ by 2020 with the condition without foreign aid, and by $41 \%$ with foreign aid based on the calculation of emissions in 2005 based on an accurate and careful calculation of consultants McKinsey. But on the other side of the researchers and non-governmental (NGO) which says that the calculation of the $26 \%$ is only based on the efforts of President Yudhoyono to be able to attract the attention of the international world by defeating the commitment of other developing countries such as India and China .

Indonesia as a country that became a third contributor to global emissions from the forestry sector is absolutely the main subject of the application of REDD regime. This potential was used by Indonesia in 2009 that Indonesia became the first country to have special regulations to carry out the steps towards REDD adjustment in the presence of the Minister of Forestry Regulation No. P30/Menhut-II/2009 on Procedures for Reducing Emissions from Deforestation and Degradation forests (REDD) .

The issue of implementation of REDD in Indonesia alone reap some of the responses of the various parties in Indonesia. Indonesian Friends of the Earth (WALHI) said that the REDD mechanism is only an instrument of transfer of the international community's attention on climate change. REDD will only shift the issues systematically developing countries to be more active in mitigation efforts than with mitigation actions in developed countries as the main contributor. In the intra-generation equity perspective this course will give you the value of climate justice is not symmetric between developed and developing countries. In the Indonesian context, there are some important things that make REDD+ to be worth discussing this issue.

First, historically Indonesia can be said is the birthplace of REDD+ because for the first time the REDD+ scheme discussed in full at the Conference of the Parties ( CoP ) to 13 of the United Nations Framework Convention on Climate Change ( UNFCCC ) in Bali, Indonesia in December 2007. One of the important backgrounds in the REDD+ regime is as an instrument of increasing economic progress of developing countries. In the Copenhagen Accord stressed that the implementation of REDD+ should be able to provide positive incentives for countries implementing the REDD+ program.

Furthermore, the importance of Indonesia's position in the discussion of REDD+ is also supported by the fact that Indonesia is a tropical forest nation's third largest in the world after Brazil and Congo. In a release issued by the Ministry of Forestry Republic of Indonesia, there are at least $60 \%$ of the total land area is forest area in Indonesia. According to official data published in Forestry Statistics 2007, the Indonesian forest area reached $133964685 \mathrm{Ha}$. While the record count conducted by FAO in 2005 which said that the Indonesian forest area is 88.495 million hectares, according to the calculations differently Forest Watch Indonesia, which states that the total area of only 83.655 million hectares of Indonesia's forests.

Finally, Indonesia's position became much more important in the discussion of REDD+ because once the title as one of the third largest emitter of CO2 emissions from entering if LULUF sector. It is important to note that according to official data from the Ministry of Forestry that the rate of deforestation in Indonesia reached 1,089,560 ha / year, so that puts Indonesia as one of the countries with the highest deforestation rates in the world. This situation has contributed significantly to the increase in global emissions originating from LULUF estimated at 1.65 Gt per year .In anticipation of the climate change 
issue, especially with the strong encouragement of the international community to include forests in the reduction of emissions from deforestation and forest degradation to enter into a climate change mitigation strategy in the institutional form. To Indonesia after the emission reduction commitments by $26 \%$ without foreign aid and $41 \%$ by foreign aid it is increasingly important to present mitigation instruments through a forest ecosystem.

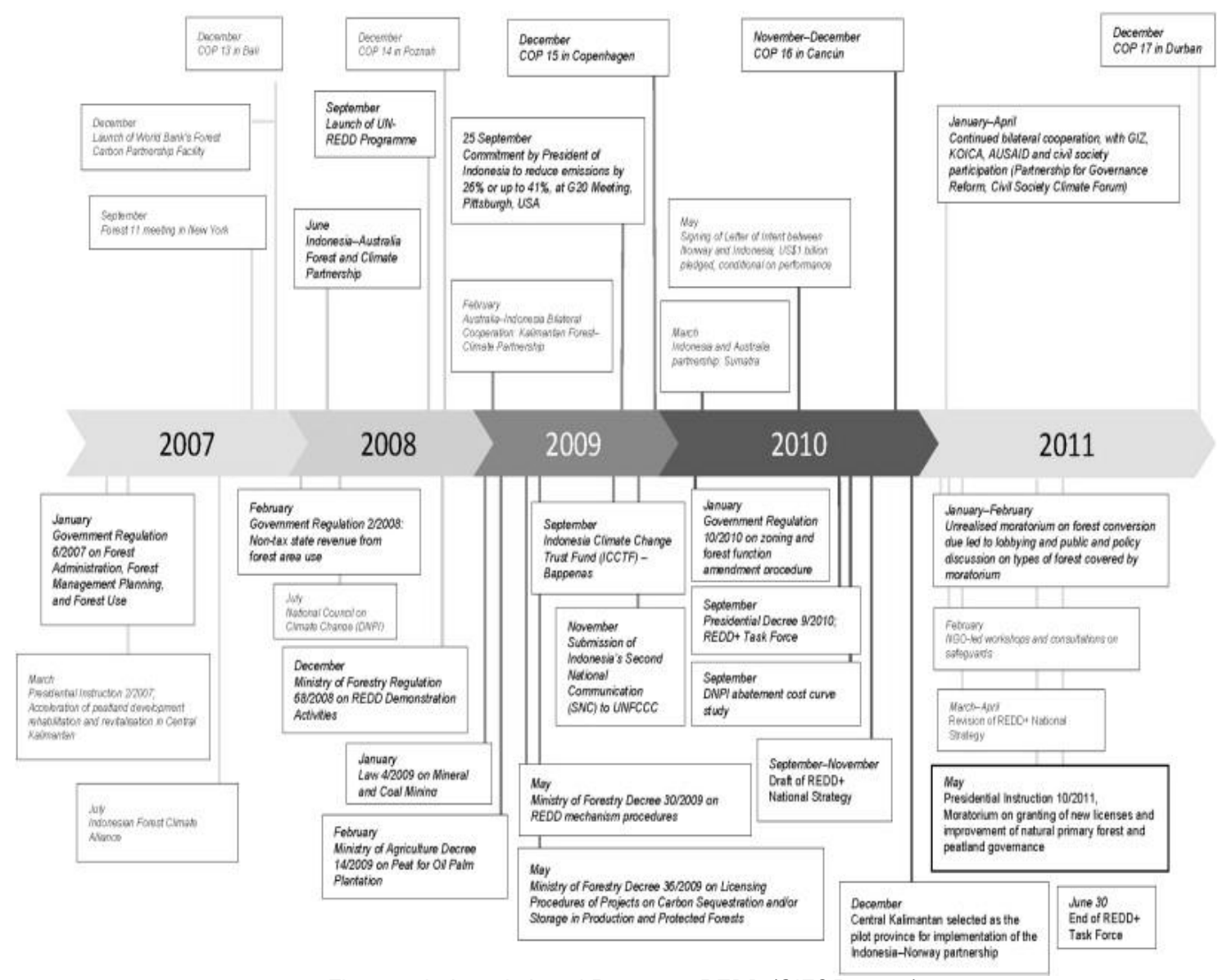

Figure 1. Indonesia Legal Response REDD (CIFOR, 2009)

REDD+ as one of the forest-based mitigation instruments have a strategic position in this regard. Developed countries such as Norway was concerned with providing assistance amounting to 1 billion U.S. dollars in several stages given the amount of 200 million dollars in the preparation phase / identification status of science and technology and related policy in the period 2007-2008 and the second phase in the preparation stage science and technology and policy REDDI / REDDI Readiness in 2009 to 2012 and the remaining $\$ 800$ million dollars at the end of the current stage of full implementation of the rules REDD COP at the time to be part of the scheme of Post-2012 Climate Change Convention.

From the aspect of legal policy, Indonesia has a unique regulation at the time of his absence at the national level to facilitate the implementation of REDD+ as a whole. The regulations governing REDD in Indonesia only legal instrument contained in Regulation of the Minister of Forestry Minister Regulation No. 30 Year 2009 on Procedures for Reducing Emissions from Deforestation and Forest Degradation (REDD). This regulation consist of 12 (twelve chapters) and 23 (twenty three) article covering: Definition; Aims and Objectives; Location and Performers; Requirements REDD; Application Procedures, Evaluation and Approval; Term; Rights and Obligations; Determination reference Emissions, Monitoring and Reporting; Verification and Certification; Distribution Incentives and liabilities; Transitional, and Final Provisions.

Based on Indonesia Legal System Hierarchy, the position of the Minister Regulation is not recognized in the arrangement of the type of legislation in the positive law as referred to in Article 7, paragraph 1 of Law No. 11 Year 2012 on the Establishment of Laws - laws that govern the type and hierarchy of laws - laws into Law Constitution of the Republic of Indonesia of 1945 the People's Consultative Assembly Decree; Undang-Undang/Peraturan in Lieu of Law; government regulation; Presidential Regulation; Provincial Regulation, and Regulation District / City.

The existence of a valid regulation upon regulation has been the presence on it beforehand. Minister Decree No. 30 of 2009 as a self-contained several legal disability.

First, in the system of international environmental law to date has not been there a rule binding and enforceable in a clear and definite obligations regarding REDD. Therefore the preamble of PERMENHUT No. 30 of 2009 which refers to the outcome Conference of the Parties 13 in Bali as a follow-up basis then this violates the provisions of international agreements that do not make the conference as a result of 
meeting the basic legal act transformation. In this context it should be the existence of a Letter of Intent between the Government of Indonesia and the Kingdom of Norway became the basis of a referral.

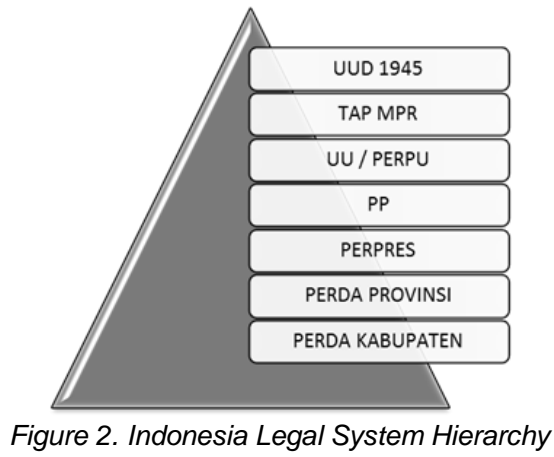

Second, the presence of the Minister of Forestry No. 30 of 2009 is a leap of legal forms for the administration of the President as the highest state authority is not involved whereas under Article 17 of the 1945 Constitution that the President in carrying out his duties assisted by a minister - the minister in charge of certain affairs. So the existence of PERMENHUT No. 30 of 2009 is constitutionally flawed.

\section{Conclusion}

President Susilo Bambang Yudhoyono get warm applause when Indonesia expressed its commitment to undertake measures to reduce emissions by $26 \%$ without foreign aid and $41 \%$ by foreign aid in 2009 at the G20 meeting. Instantly warm welcome greeted commitment instrument is then registered in the Copenhagen Accord. However, if examined further, Indonesia has a commitment benchmark (baseline) of the absurd that is only based Business As Usual (BAU). Indeed, in practice it is not determined by reference to the type of baseline model of bottom-up like this. BAU models have drawbacks when used starting age tends to be set up and down in accordance with the realization that occurs in the field. Of some countries listed in Copenhagen Accord commitment shown that baseline is a measure of the time more clearly. By comparison Australia has a commitment of 5-25\% below emissions in 2000 , while China has a commitment of 40-45\% below 2005 emissions in the emissions intensity. It sounds more real and can be measured with certainty rather than just SMELL that can be lowered or raise at will from the state committed. In addition, the structure of regional autonomy should be regarded as typical Indonesian one challenge. Based on information contained in the official website of the Secretariat of the National Action Plan for Greenhouse Gases, recorded from 33 (thirty three ) provinces in Indonesia as many as 17 (seventeen) provinces have completed the Regional Action Plan Greenhouse Gas ( GHG RAD ) and has published in the form of a regulation, namely Jambi, iN Yogyakarta, Central Java, DKI Jakarta, Central Sulawesi, North Sumatra, East Kalimantan, South Sumatra, West Sumatra, Riau, East Java, West Java, West Kalimantan, Southeast Sulawesi, Gorontalo, Kep. Bangka Belitung and West Sulawesi. While nine (9) provinces have completed RAD GRK but not pouring in the form of regulation that the Governor of South Sulawesi, Aceh, Bengkulu, Lampung, Banten, South Kalimantan, Bali, West Nusa Tenggara and East Nusa Tenggara. As for the remaining seven (7) provinces have not done an inventory of greenhouse gases. This is a challenge in the form of greenhouse gas mitigation efforts at the national level especially with the regime of local autonomy has delegated some powers to the regions.

Have a set of expectations and challenges above can be realized and answered by the current government because of the impact of climate change is not only suffered by people today, but also future generations.

\section{References}

Agora. (1992). What Obligation Does Our Generation Owe to the Next? An Approach to Global Environmental Responsibility, American Journal of International Law January,

Bodansky, Daniel. (1993). "The United Nations Framework Convention on Climate Change: A Commentary", 18 Yale Journal. International Law. 451

Coase, Ronald H. (1960). The Problem of Social Cost, Journal Law and Economic.

Harris, Paul G. (2007). Collective Action on Climate Change: The Logic of Regime Failure, 47 Natural. Resources Journal. 195.,

(2008). "Climate Change And The Impotence Of International Environmental Law: Seeking A Cosmopolitan Cure". Penn State Environmental Law Review Winter

Koh, Harold Hongju. (1997) Why Do Nations Obey International Law?, 106 Yale Law .Journal. 2599

Nollkaemper, Andre. (1996) "Protecting Forest through Trade Measure: The Search for Substantive Benchmarks", Georgetown International Environmental Law Review, Vol. 8

Pardy, Bruce. (2004). "The Kyoto Protocol: Bad News for the Global Environment", Journal of Environmental Law and Practice 
Sloane, George B dan Barry N. Rosen. (1995). "Environmental Product Standards, Trade and European Consumer Good Marketing: Processes, Threats and Opportunities," Columbia Journal of World Business, Vol. 30, No. 1

Taylor. Prue., (1998). "An Ecological Approach To International Law: Responding To Challenges Of Climate Change"

Thürer, Daniel. (1999). The "Failed States" and International Law , International Review of the Red Cross

Weiss, Edith Brown. (1993). International Environmental Law: Contemporary Issues and the Emergence of a New World Order, 81 Georgia Law Journal. 675, 679 
REDD Policy in Indonesia: Reality in Grey Area

42 | IJPD Volume 1 No 1 September 2014, 35-42 